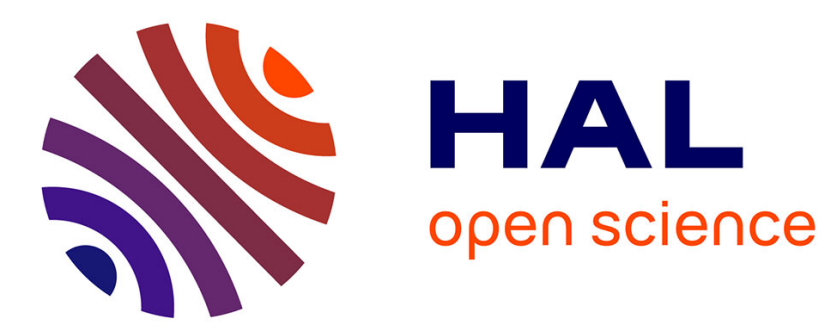

\title{
Mesoporous Silica Colloids: Wetting, Surface Diffusion, and Cationic Surfactant Adsorption
}

Elise Azar, Christophe Blanc, Ahmad Mehdi, Maurizio Nobili, Antonio Stocco

\section{To cite this version:}

Elise Azar, Christophe Blanc, Ahmad Mehdi, Maurizio Nobili, Antonio Stocco. Mesoporous Silica Colloids: Wetting, Surface Diffusion, and Cationic Surfactant Adsorption. Journal of Physical Chemistry C, 2019, 123 (43), pp.26226-26235. 10.1021/acs.jpcc.9b05798 . hal-02341812

\section{HAL Id: hal-02341812 \\ https://hal.science/hal-02341812}

Submitted on 31 Oct 2019

HAL is a multi-disciplinary open access archive for the deposit and dissemination of scientific research documents, whether they are published or not. The documents may come from teaching and research institutions in France or abroad, or from public or private research centers.
L'archive ouverte pluridisciplinaire $\mathbf{H A L}$, est destinée au dépôt et à la diffusion de documents scientifiques de niveau recherche, publiés ou non, émanant des établissements d'enseignement et de recherche français ou étrangers, des laboratoires publics ou privés. 


\title{
Mesoporous Silica Colloids: Wetting, Surface Diffusion and Cationic Surfactant Adsorption
}

\author{
Elise Azar, ${ }^{\mathrm{a}, \mathrm{b}}$ Christophe Blanc, ${ }^{\mathrm{a}}$ Ahmad Mehdi, ${ }^{\mathrm{c}}$ Maurizio Nobili ${ }^{\mathrm{a}}$ and Antonio Stocco ${ }^{\text {a,b }}$ \\ ${ }^{a}$ Laboratoire Charles Coulomb (L2C), University of Montpellier, CNRS, Montpellier, France \\ ${ }^{\mathrm{b}}$ Institut Charles Sadron (ICS), University of Strasbourg, CNRS, Strasbourg, France \\ ${ }^{\mathrm{c}}$ Institut Charles Gerhardt (ICGM), University of Montpellier, CNRS, ENSCM, Montpellier, France \\ *stocco@unistra.fr, Telephone: +33 (0)388414113, Fax: +33 (0)388414099
}

\section{ABSTRACT}

We have investigated the wetting and surface diffusion of mesoporous colloidal silica particles at the water surface; and the adsorption of cationic cetyltrimethylammonium $\left(\mathrm{CTA}^{+}\right)$surfactant on these particles. Porous silica colloids diffuse at the surface of water and in the volume, interacting with cationic surfactants that can adsorb inside the pores of the particles. We observed that surfactant adsorption on mesoporous silica depends dramatically not only on the particle pore size but also on specific counterion effects. We measured striking differences both on a macroscopic property of the interface, i.e. surface tension, and also at a single particle level by evaluating the translational diffusion of partially wetted particles at the fluid interface. We varied the pore size from 2 to $7 \mathrm{~nm}$ and explored the effects of ions owing different hydration number and kosmotropic/chaotropic character. At concentrations lower than the critical micellar concentration, we evidence that cationic surfactants adsorb on silica as surface micelles and surfactant adsorption inside the pores occurs only if the pore diameter is larger than the size of surface micelles. With a view to understand the surprising different adsorption behavior of $\mathrm{CTA}^{+} \mathrm{OH}^{-}$and $\mathrm{CTA}^{+} \mathrm{Br}^{-}$on porous silica particles, we investigated the effect of counterions on the surfactant adsorption on porous silica colloids by tuning the $\mathrm{pH}$ and the counterion properties.

\section{INTRODUCTION}

Cationic surfactants are widely used in many industrial and fundamental research fields ranging from cosmetics, fabrics, nanoparticles synthesis, DNA folding, self-assembly and mesoporous material fabrication. ${ }^{1,2}$ Besides these applications, the fate of cationic surfactants and the resulting waste in water is an important issue, since cationic surfactant contamination of water represents an real environmental problem. ${ }^{3}$ Current methods to remove surfactants from water involve the use of organophilic clays, flocculants or carbon beds. ${ }^{4-8}$ In many separation methods, surfactant removal by adsorption onto solid substrates is required. Hence, both large surface areas and an effective attraction between the surfactant and the solid are necessary to drive soluble surfactants adsorption on the solid boundaries.

Adsorption of cationic surfactants on planar solid surfaces has been investigated for several surfactantsubstrate systems. For cetyltrimethylammonium $\left(\mathrm{CTA}^{+}\right)$surfactants on silica surfaces, different adsorption regimes are found as a function of the surfactant concentration, surface charge and 
hydrophobic interaction. ${ }^{9,10}$ At low concentrations, surfactant may adsorb onto the silica surface as a monolayer, as defective bilayers or as surface micelles. ${ }^{11,12}$ These micellar structures are flattened by the surface and possess a thickness of $3.5 \mathrm{~nm}$ and a lateral size of $9 \mathrm{~nm} .{ }^{10}$ Upon increasing the concentration, bilayers may form due to the interaction between the hydrophobic chains. It is important to notice that the interfacial self-assembled structures usually appear at a concentration lower than the usual critical micellar concentration (CMC) in the volume. ${ }^{11}$ For $\mathrm{CTA}^{+}$surfactants at concentrations $C$ lower but close to CMC, surface excess concentrations $\Gamma$ between $\approx 1$ and $\approx 2 \mathrm{mg} / \mathrm{m}^{2}$ have been reported. ${ }^{11,13-15}$

As pointed out before, solid substrates with large specific areas are required for adsorption in order to separate surfactants from clean water. In this context, porous particles are ideal candidates given the large surface/volume ratio, which can be tuned by the pore size and volume fraction. ${ }^{16,17}$ However, adsorption inside a pore strongly differs from the adsorption on a planar interface. Pore size and morphology affect the adsorption process, which depends on differences in pressure and physicochemical properties inside and outside the pores. ${ }^{18}$

Non-ionic surfactants adsorption onto mesoporous silica particles has been widely investigated by Findenegg and coworkers. ${ }^{19-22}$ Bilayers formation and other structures inside the pores has been reported. Very few experimental investigations can be found in the literature for the adsorption of cationic surfactants onto mesoporous silica. A small angle neutron scattering investigation reported some preliminary experiments for $8 \mathrm{~nm}$ pore size mesoporous silica at $\mathrm{pH}=9$ where an increase of cationic surfactant adsorption occurs if the ionic strength is increased. ${ }^{23}$ Cationic surfactant interacting with silica nanoparticles have been also recently investigated. ${ }^{1,24-26}$

Here, we have investigated the wetting and diffusion of porous silica colloids, and the adsorption of cationic surfactants on porous colloidal particles. Porous colloids of different pore sizes are deposited both in the bulk and at the interface. By varying pore size, surfactant concentration and investigating counterion effects we aim at controlling $\mathrm{CTA}^{+}$cationic surfactant adsorption. These results could be used in order to develop a strategy to clean the surface and the volume of water with micron sized particles, which are small enough to perform Brownian motion and rapidly diffuse at the interface (and in the volume) but also large enough to slowly sediment. These porous colloids may be ideal candidates for an efficient removal of surfactants at low concentrations and present the advantage to be easily removed after decontamination by sedimentation or flotation. Note that larger particles are difficult to adsorb at the interface and may sediment very fast; whilst nanoparticles may remain dispersed in water due to the strong Brownian motion and cannot be separated by gravity or adsorption on bubbles as in flotation.

\section{MATERIALS AND METHODS}

Materials. All chemicals, except for the in-house synthetized colloids, were purchased from Sigma Aldrich and used without further purification. Two surfactants were investigated: cetyltrimethylammonium bromide $\mathrm{CTA}^{+} \mathrm{Br}^{-}$(CAS 57-09-0, molecular weight $M_{w}=364.45 \mathrm{~g} / \mathrm{mol}$ ) and cetyltrimethylammonium hydroxide $\mathrm{CTA}^{+} \mathrm{OH}^{-}\left(10 \mathrm{wt} . \%\right.$ in $\mathrm{H}_{2} \mathrm{O}$, CAS $\left.505-86-2, M_{w}=301.55 \mathrm{~g} / \mathrm{mol}\right)$. Three different batches of porous silica particles were also employed. The first two consist of spherical mesoporous silica colloids (CAS 7631-86-9) with an average radius $\bar{R}=1.23 \pm 0.10 \mu \mathrm{m}$ (measured by scanning electron microscopy, SEM) and nominal pore diameter $d=2 \mathrm{~nm}$ and $d=4 \mathrm{~nm}$ and a specific area $S_{A}=1000 \pm 100 \mathrm{~m}^{2} / \mathrm{g}$ for $d=2 \mathrm{~nm}$ and $S_{A}=350 \pm 50 \mathrm{~m}^{2} / \mathrm{g}$ for $d=4 \mathrm{~nm}$. A third batch of nonspherical mesoporous silica particles was synthetized in the laboratory. These last particles are currently 
called Santa Barbara amorphous-15 silica (SBA-15). The average pore diameter is larger than the previous ones: $d=7 \mathrm{~nm}$ measured by volumetric nitrogen sorption isotherms. Stable particle dispersions were obtained by sonication of $1.2 \mathrm{mg} / \mathrm{mL}$ dispersions in an ultrasound bath for one hour. We measured the Feret diameter ${ }^{27}$ of these particles by scanning electron microscopy, which leads to an equivalent radius $\bar{R}=1.96 \pm 0.97 \mu \mathrm{m}$ (i.e. half of the Feret diameter). The pores are about a micron long and connected via mesoporous walls. A total specific area of $750 \pm 50 \mathrm{~m}^{2} / \mathrm{g}$ was evaluated by BrunauerEmmett-Teller (BET) method. Pore size distributions were determined by the (Barrett, Joyner, Halend) BJH method. ${ }^{28}$ Mesoporous walls contribute significantly to the total specific area in terms of microporosity (size $<1-2 \mathrm{~nm}$ ). We evaluate a total specific area $S_{A}=225 \pm 25 \mathrm{~m}^{2} / \mathrm{g}$ for the $d=7 \mathrm{~nm}$ pore size (See Figure S1 in Supporting Information, SI).

$\mathrm{NaOH}, \mathrm{NaBr}, \mathrm{NaCl}$ salts were used as received. Fresh Milli-Q water was used throughout this work. Experiments were carried out at room temperature $\mathrm{T}=22{ }^{\circ} \mathrm{C}$.

Surface tension and sessile drop contact angle. Surface tension was used to measure surfactant adsorption on porous particles. All measurements were performed in a $9 \mathrm{~cm}$ diameter polystyrene Petri dish containing a volume $V=35 \mathrm{~mL}$ of surfactant solutions at different concentrations $C$ and a fixed mass (1.2 $\mathrm{mg}$ ) of porous particles. For planar aqueous surfaces contained in a Petri dish, surface tension was measured by the Wilhelmy plate method (KSV NIMA, Biolin Scientific) using a filer paper plate. In order to evaluate the interfacial tensions of the silica-surfactant solutions-gas systems, we also measured the surface tension of aqueous solutions and the advancing contact angle $\theta$ of sessile drops by a profile analysis tensiometer (PAT, Sinterface, Germany). A typical volume of the aqueous drop in PAT experiments is $15 \mathrm{~mm}^{3}$. Series of experiments were repeated at least three times and show a good reproducibility. For interfacial tension measurements, the standard deviations of the data obtained in different experimental campaigns lay between 1 and $3 \mathrm{mN} / \mathrm{m}$, which can be related to the experimental protocols: particle deposition, aging of particle dispersions and surfactant solutions (i.e. maximum 5 days).

Particle dispersion deposition. The final chosen method adopted to deposit porous particles at the interface is to drop $1 \mathrm{~mL}$ of a $1.2 \mathrm{mg} / \mathrm{mL}$ particle suspension on a tilted glass slide placed at the air-water interface and let it slip. ${ }^{29}$ Particle density at the interface can be calculated by counting the particle number using optical microscopy. For all porous particle systems, we evaluated an average surface coverage of $6.5 \pm 2$ particles per $\mathrm{mm}^{2}$ (if $1.2 \mathrm{mg}$ of silica porous particles are added in the Petri dish). From the latter value, one can estimate the ratio between the total number of particles $N_{t o t}$ and the ones trapped at the surface $N_{s}: N_{t o t} / N_{s} \approx 10^{6}$, which is very high, meaning that only few particles stay at the interface. We have put many efforts to find protocols to increase the number of particles remaining at the airaqueous solution interface and try several methods. However, protocols involving spraying or the use of additional volatile solvents were discarded since they do not allow the control of the particles numbers or introduce additional sources of contamination and uncertainties. It is important to note that even if $N_{t o t} / N_{s}$ $\approx 10^{6}$, the amount of particles at the interface is non-negligible for the adsorption of soluble surfactants, which accumulate preferentially at the interface but they are also present in the bulk, see Figure S2 in SI.

Particle contact angle by gel trapping. We measured the particle contact angle of porous silica colloids using a gel trapping technique. ${ }^{30}$ Few microliters of a diluted solution of particles were added to a gelled solution of Phytagel (CAS 71010-52-1, Sigma Aldrich) in a small container. After heating up the gel to the liquid state, the particles get trapped at the interface. Going back to the room temperature, a UV-glue was used to transfer the particles from the gel to the glue substrate. The contact angle was measured using 
scanning electron microscopy images of the transferred particles on the solidified glue at their complementary contact angle positions.

Particle tracking. Bright field optical microscopy was used for particle tracking. Experiments were performed in an upright Leica optical microscope mounted on an anti-vibration table. Images of isolated particles were recorded using a CMOS camera (Orca Flash 4.0, Hamamatsu) at rates of 80 or 100 frames per second using objectives of different magnifications $(\times 63$ and $\times 100)$. Tracking of the particle location was done by an $I D L$ routine or by using an image correlation-based approach ("Stat Tracker St. Andrews") implemented in Labview (National Instruments).

Zeta potential and $\mathrm{pH}$ measurements. We measured the zeta potential $\zeta$ (Zetasizer Nano ZS, Malvern Instruments) and the $\mathrm{pH}$ of the particle dispersions in pure water or in the presence of surfactants. For porous silica colloids dispersions, a $\mathrm{pH}=6.4$ was always measured in pure water.

\section{RESULTS AND DISCUSSION}

\section{Interfacial tensions of $\mathrm{CTA}^{+} \mathrm{Br}^{-}$and $\mathrm{CTA}^{+} \mathrm{OH}^{-}$at the liquid-gas and solid-liquid interfaces}

We started characterizing the adsorption of $\mathrm{CTA}^{+}$surfactants on non-porous silica by evaluating the interfacial tension between silica and the aqueous surfactant solutions, $\gamma_{\mathrm{SL}}$. Young equation for a sessile drop of aqueous surfactant solutions on a silica substrate in air reads:

$\gamma_{\mathrm{SG}}=\gamma_{\mathrm{SL}}+\gamma_{\mathrm{LG}} \cos \theta$,

where the subscripts $\mathrm{S}, \mathrm{L}$ and $\mathrm{G}$ represent solid, liquid and gas respectively. One can evaluate $\gamma_{\mathrm{SL}}$ measuring the interfacial tension $\gamma_{\mathrm{LG}}$, the sessile drop static contact angle $\theta$ and assuming that $\gamma_{\mathrm{SG}}$ is a constant (and does not vary with the surfactant concentration). Surface tension at the air-aqueous solution interface $\gamma_{\mathrm{LG}}$ for $\mathrm{CTA}^{+} \mathrm{Br}^{-}$and $\mathrm{CTA}^{+} \mathrm{OH}^{-}$surfactant was measured by the Wilhelmy plate technique and pendant drop tensiometry. The two methods lead to very similar results as shown for a series of experiments in Figure 1A. The evolution of $\gamma_{\mathrm{LG}}$ as a function of the surfactant concentration $C$ for both surfactants shows no significant difference. In addition, $\gamma_{\mathrm{LG}}$ values are stable and do not change in a typical experimental time range of $3000 \mathrm{~s}$ (inset of Figure 1A). Sessile drops made with surfactants solutions were deposited on clean glass slides and their contact angles $\theta$ were also evaluated by imaging the drop profile (and the $\cos \theta$ is plotted in the inset of Figure $1 \mathrm{~B}$ for a series of experiment). ${ }^{31}$ Hence, $\gamma_{\mathrm{SL}}$ can be calculated from eq. 1 with $\gamma_{\mathrm{SG}}=68.5 \mathrm{mN} / \mathrm{m}$ as reported by Binks et al. ${ }^{32}$ for silica surfaces showing water contact angle similar to our experiments. Unexpectedly the silica-aqueous solution interfacial tension $\gamma_{\mathrm{SL}}$ shows a non-monotonic behavior if the surfactant concentration is increased. ${ }^{33,34}$ For $C \geq 0.1 \mathrm{mM}, \gamma_{\mathrm{SL}}$ increases if $C$ increases, instead of decreasing as $\gamma_{\mathrm{LG}}$. Hence, the Gibbs adsorption valid for ideal dilute solutions for $C<\mathrm{CMC}(\approx 0.8-0.9 \mathrm{mM})^{10,35}$ can be applied only for the air-liquid interface, where a surface concentration $\Gamma \approx 1 \mathrm{mg} / \mathrm{m}^{2}$ at the CMC can be evaluated. ${ }^{36}$ For $C<0.1 \mathrm{mM}$ at the solidliquid interface, one could also observe a tiny decrease of the interfacial tension which could correspond to an increasing accumulation of non-interacting surfactants at the solid-liquid interface. ${ }^{37}$ However for $C$ $\geq 0.1 \mathrm{mM}$, the increase of $\gamma_{\mathrm{sL}}$ points to the formation of self-assembled structures as bilayers ${ }^{38}$ or surface micelles, which form because of the hydrophobic interactions between surfactant tails. Note that the 
concentration at which the interfacial tension $\gamma_{\mathrm{SL}}$ increases is about 10 times lower that the $\mathrm{CMC}{ }^{10}$ An increase of the interfacial tension $\gamma_{\mathrm{SL}}$ reveals that the surface is increasing in hydrophobicity due to the presence of hydrophobic surfactant groups. As already pointed out in the Introduction, the presence of bilayers or surface micelles on planar silica surfaces has been widely reported but to the best of our knowledge was never connected to a minimum in the interfacial tension $\gamma_{\mathrm{SL}}$.

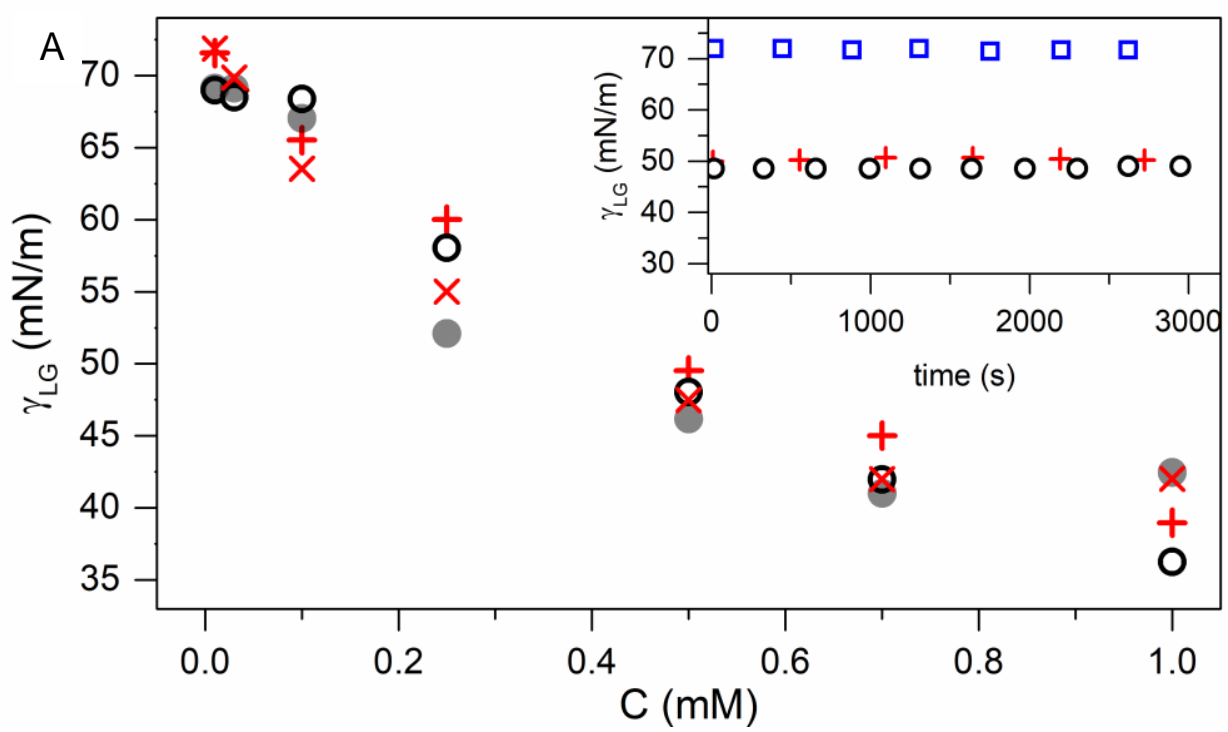

171

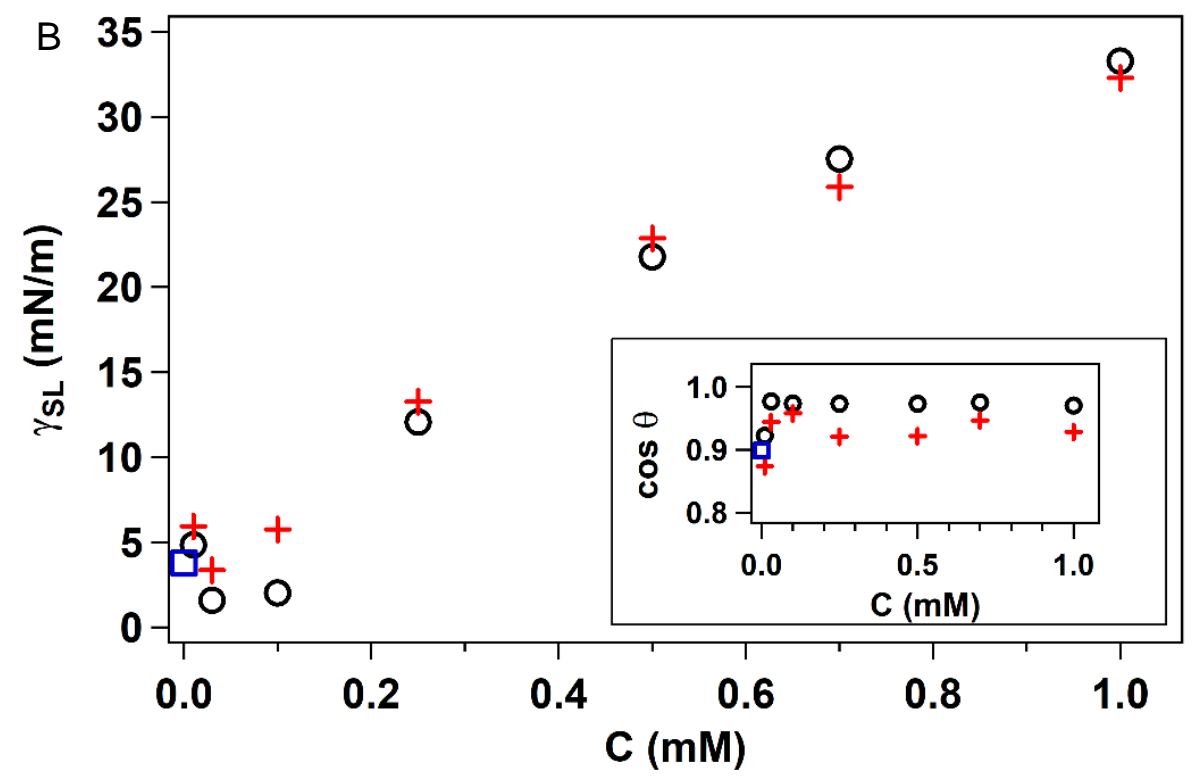

173

Figure 1. (A) Liquid-gas interfacial tension of $\mathrm{CTA}^{+} \mathrm{Br}^{-}(+, \square)$ and $\mathrm{CTA}^{+} \mathrm{OH}^{-}(-$, , ) as a function of the 175 concentration obtained by pendant drop tensiometry $(+,-)$ and by Wilhelmy plate method $(\square$, , ); inset: interfacial tension as a function of time for pure water $(\forall)$ and $\mathrm{CTA}^{+} \mathrm{Br}^{-}(+)$and $\mathrm{CTA}^{+} \mathrm{OH}^{-}(-)$at $C=0.5 \mathrm{mM}$. (B) Solid-liquid 
interfacial tension $\mathrm{CTA}^{+} \mathrm{Br}^{-}(+)$and $\mathrm{CTA}^{+} \mathrm{OH}^{-}(-)$evaluated by the Young equation and advancing contact angle measurement of sessile drops on silica (inset). Data for pure water $(\forall)$ are also shown.

\section{Porous particles at the interface}

The contact angle of porous particles at the gas-liquid interface was measured by a gel trapping method (see Materials and Methods). Figure 2 shows images of particles at their complementary contact angle positions. We have also observed some crater shape footprints on the solidified substrate, which correspond to particles possessing very low contact angles. For spherical porous particle, we measured particle contact angle $\alpha=47^{\circ} \pm 6^{\circ}$ for $d=2 \mathrm{~nm}$ and $\alpha=52^{\circ} \pm 14^{\circ}$ for $d=4 \mathrm{~nm}$ (Figure 2A and B). Nonspherical porous particles show also a finite immersion at the air-water interface that is comparable to the contact angle observed for the spherical porous particles.
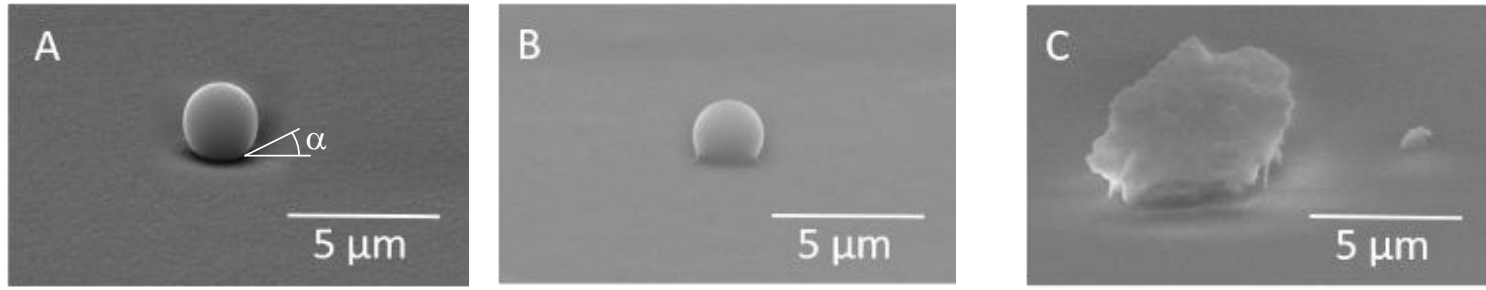

Figure 2. SEM images of gel trapped $\bar{R}=1.23 \mu \mathrm{m}$ spherical mesoporous silica colloids $d=2 \mathrm{~nm}$ (A) and $d=4 \mathrm{~nm}$ (B); and a non-spherical silica particle of equivalent radius $\bar{R}=1.96 \mu \mathrm{m}$ (diameter $=3.92 \mu \mathrm{m})$ and $d=7 \mathrm{~nm}(\mathrm{C})$.

It is important to notice that the measured contact angle of a sessile water drop on silica, $\theta \approx 26^{\circ}$, is significantly lower than the contact angles of porous silica particles shown in Figure 2: $\alpha>\theta$. In order to explain this result, we start discussing the partial wetting state of porous particles and compare it to the reference case of a bare solid spherical particle, see Figure 3. For a bare particle, the equilibrium of interfacial tensions leads to the Young equation (see equation 1). For smooth and homogenous surfaces, the bare solid micron-sized particle contact angle should be identical to the contact angle of a sessile liquid drop on a flat solid substrate: $\alpha_{B}=\theta{ }^{39}$ In the framework of the Cassie-Baxter model valid for composite interfaces, two different scenario can be considered for porous particles at the interface.

In the first case, we consider that the pores of the particles are completely filled by the liquid. In this case, the particle interfacial tensions $\gamma_{\mathrm{SG}}$ and $\gamma_{\mathrm{SL}}$ change if compared to the bare particle case. The interfacial tension of the particle exposed to the liquid will be reduced from $\gamma_{\mathrm{SL}}$ to $f \gamma_{\mathrm{SL}}$, where $f$ is the solid area fraction on the particle surface, see Figure 3. The particle surface exposed to the gas phase can be regarded as a composite interface made of solid and liquid. ${ }^{39}$ The resulting equilibrium of interfacial tensions reads:

$f \gamma_{\mathrm{SG}}+(1-f) \gamma_{\mathrm{LG}}=f \gamma_{\mathrm{SL}}+\gamma_{\mathrm{LG}} \cos \alpha$.

210 Except for $f$, all the other variables in equation 2 are measured. In pure water, $\gamma_{\mathrm{SG}}=68.5 \mathrm{mN} / \mathrm{m}, \gamma_{\mathrm{LG}}=$ $21172.5 \mathrm{mN} / \mathrm{m}$ and $\gamma_{\mathrm{SL}}=4 \mathrm{mN} / \mathrm{m}$ (Figure 1). According to equation 2, $\alpha$ decreases if $f$ decreases and the Young equation is recovered if $f=1$. Actually for porous particles with pores completely filled by the liquid, the particle contact angle $\alpha$ is expected to be low, $\alpha<\theta$, which explains the observation of crater footprints in SEM images and the large number of particles in the volume with respect to the particles present at the interface (see Particle dispersion deposition section). Note also that the interfacial energy 
gain associated to the adsorption of a bare particle at the interface $\gamma_{\mathrm{LG}} A_{0}$ due to the removal of a bare fluid interface area $\left(A_{0}=\pi R^{2} \sin ^{2} \alpha\right)$ is strongly reduced for a porous particle given the presence of liquid inside the particle. ${ }^{39}$

A second scenario can be considered to explain the results shown in Figure 2, where $\alpha>\theta=\alpha_{\mathrm{B}}$ (Figure $3)$. In this case, the liquid is not present on the porous particle surface exposed to the gas phase. Hence, the external surface can be regarded as a composite surface made of solid and air, and the interfacial tension of this surface becomes $f \gamma_{\mathrm{SG}}$. The resulting equilibrium of interfacial tensions reads:

$f \gamma_{\mathrm{SG}}=f \gamma_{\mathrm{SL}}+\gamma_{\mathrm{LG}} \cos \alpha$

224 In this second case, the contact angle of a porous particle can be higher than the contact angle of an 225 equivalent bare particles. Equation 3 can be rewritten in the form $\cos \alpha=\frac{f\left(\gamma_{S G}-\gamma_{S L}\right)}{\gamma_{L G}}=f \cos \theta$ (see equation 1), which leads to solid area fraction $f=0.76$ for $2 \mathrm{~nm}$ and $f=0.68$ for $4 \mathrm{~nm}$ pore size porous particles.

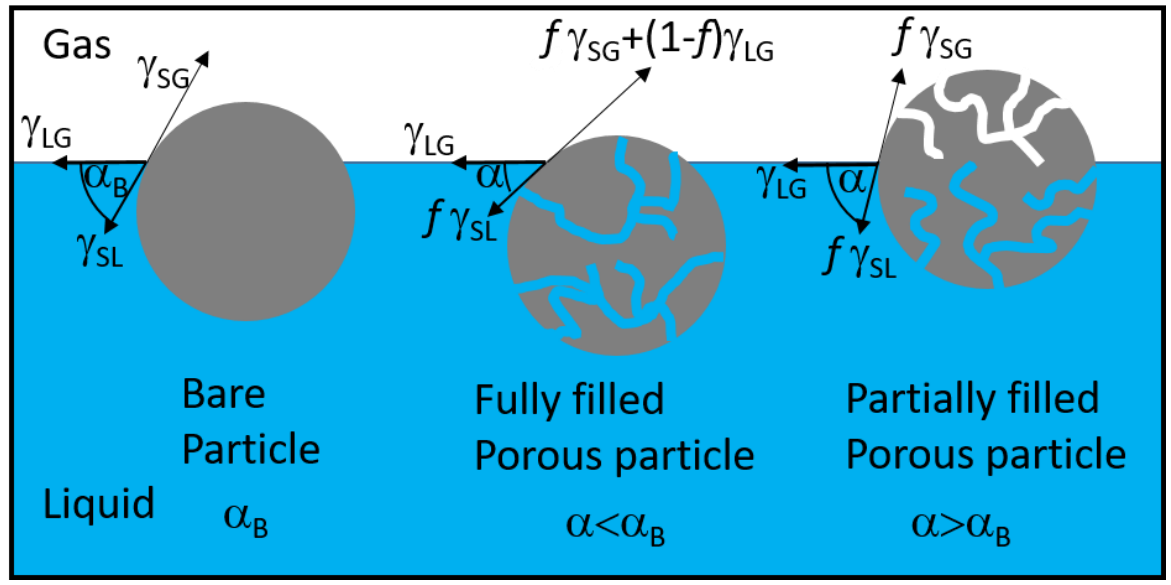

Figure 3. Sketches of a bare non-porous particle (left), a porous particle with pores completely filled by the liquid (center) and a porous particle with pores partially filled by the liquid (right) in mechanical equilibrium at the gasliquid interface.

\section{Influence of particle pore size on surfactant adsorption}

In order to measure the surfactant adsorption on porous silica colloids we performed surface tension experiments using a Wilhelmy plate apparatus. Starting from a stable interfacial tension measurement at a given surfactant concentration $C$, porous colloids are deposited at the air-aqueous solution interface via a tilted glass slide. Note that the addition of few porous colloids $(1.2 \mathrm{~g}$ in $35 \mathrm{~mL}$ water $)$ in absence of surfactants does not affect the interfacial tension $\gamma_{\mathrm{LG}}$. As a consequence of the addition of mesoporous particles, we record an increase of the liquid-gas interfacial tension connected to a surfactant removal from the aqueous solution due to the adsorption on porous silica colloids.

In Figure 4 we show a series of surface tension experiments of $\mathrm{CTA}^{+} \mathrm{Br}^{-}$and $\mathrm{CTA}^{+} \mathrm{OH}^{-}$solutions at different surfactant concentrations in the presence of a fixed number of porous silica particles of 4 and 7 $\mathrm{nm}$ pore diameters $d$. For $\mathrm{CTA}^{+} \mathrm{OH}^{-}$in the presence of the $d=4 \mathrm{~nm}$ (Figure 4A) and $7 \mathrm{~nm}$ (Figure 4B) porous silica particles, we measured a significant increase in the surface tension, which is a clear evidence 
of surfactant removal from the aqueous solution. When adding $d=4 \mathrm{~nm}$ porous silica colloids, the 246 interfacial tension increases by $8 \mathrm{mN} / \mathrm{m}, 5 \mathrm{mN} / \mathrm{m}$ and $4 \mathrm{mN} / \mathrm{m}$ for $0.25 \mathrm{mM}, 0.5 \mathrm{mM}$ and $0.7 \mathrm{mM}$ 247 respectively. As for the $d=7 \mathrm{~nm}$ porous silica colloids, the surface tension increases by $12 \mathrm{mN} / \mathrm{m}, 9$ $248 \mathrm{mN} / \mathrm{m}$ and $7 \mathrm{mN} / \mathrm{m}$ for $0.25 \mathrm{mM}, 0.5 \mathrm{mM}$ and $0.7 \mathrm{mM}$ respectively. Surprisingly, no apparent increase in 249 the surface tension with $\mathrm{CTA}^{+} \mathrm{Br}^{-}$was observed, which will be further analyzed and discussed in the 250 following sections. No adsorption for both $\mathrm{CTA}^{+} \mathrm{Br}^{-}$and $\mathrm{CTA}^{+} \mathrm{OH}^{-}$was also observed for $d=2 \mathrm{~nm}$ 251 porous silica colloids, see Figure 5. Surface tension measurements showed no variation before and after 252 adding the $d=2 \mathrm{~nm}$ porous particles (Figure 5), leading to the conclusion that a pore size of $2 \mathrm{~nm}$ is too 253 small for $\mathrm{CTA}^{+}$cationic surfactant adsorption. This result agrees with the increase of $\gamma_{\mathrm{SL}}$ shown in Figure 254 1B and connected to the formation of surface micellar structures at concentrations much lower than the 255 CMC. Surfactants may adsorb inside the pores as micellar structures and not as single molecules. The size of micelles in the bulk ${ }^{10}$ (for $C \approx \mathrm{CMC}$ ) is between 2.6 and $4.7 \mathrm{~nm}$; and for $C<\mathrm{CMC}$ the thickness of 257 surface micelles is about $3.5 \mathrm{~nm}$ for $\mathrm{CTA}^{+} \mathrm{Br}^{-}$. Hence, these dimensions are always larger than the size of $2582 \mathrm{~nm}$ and explain why adsorption is not observed in $d=2 \mathrm{~nm}$ porous particles. 

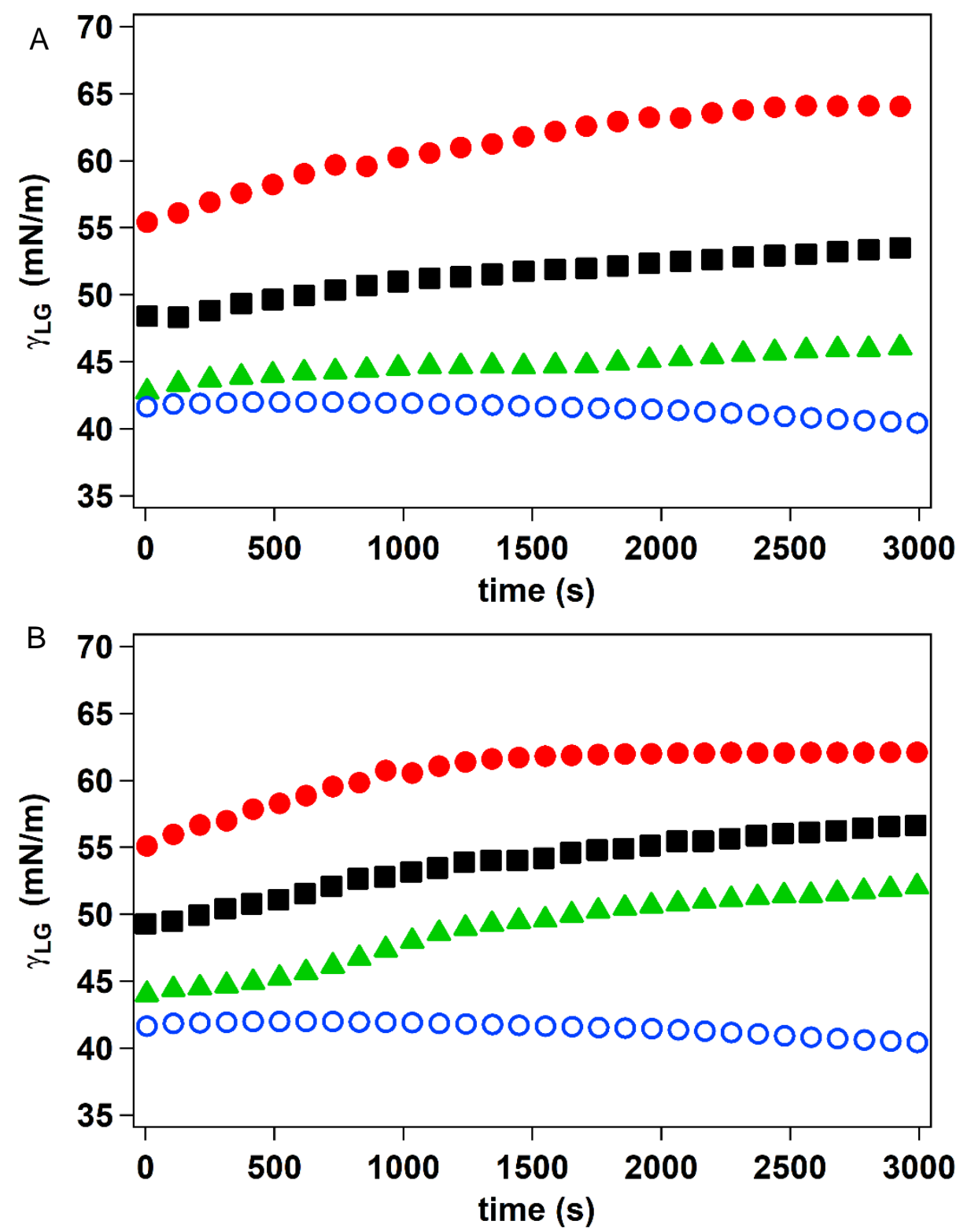

Figure 4. Liquid-gas interfacial tension as a function of time after the deposition of $d=4 \mathrm{~nm}$ porous silica particles (A) and $d=7 \mathrm{~nm}$ particles (B) at different $\mathrm{CTA}^{+} \mathrm{OH}^{-}$surfactant concentrations: $C=0.25 \mathrm{mM}(),, 0.5 \mathrm{mM}(!), 0,7$ $\mathrm{mM}(7)$; and $\mathrm{CTA}^{+} \mathrm{Br}^{-}$concentration $C=0.7 \mathrm{mM}(-) .1 .2 \mathrm{~g}$ of particles were added in $35 \mathrm{~mL}$ solution. 


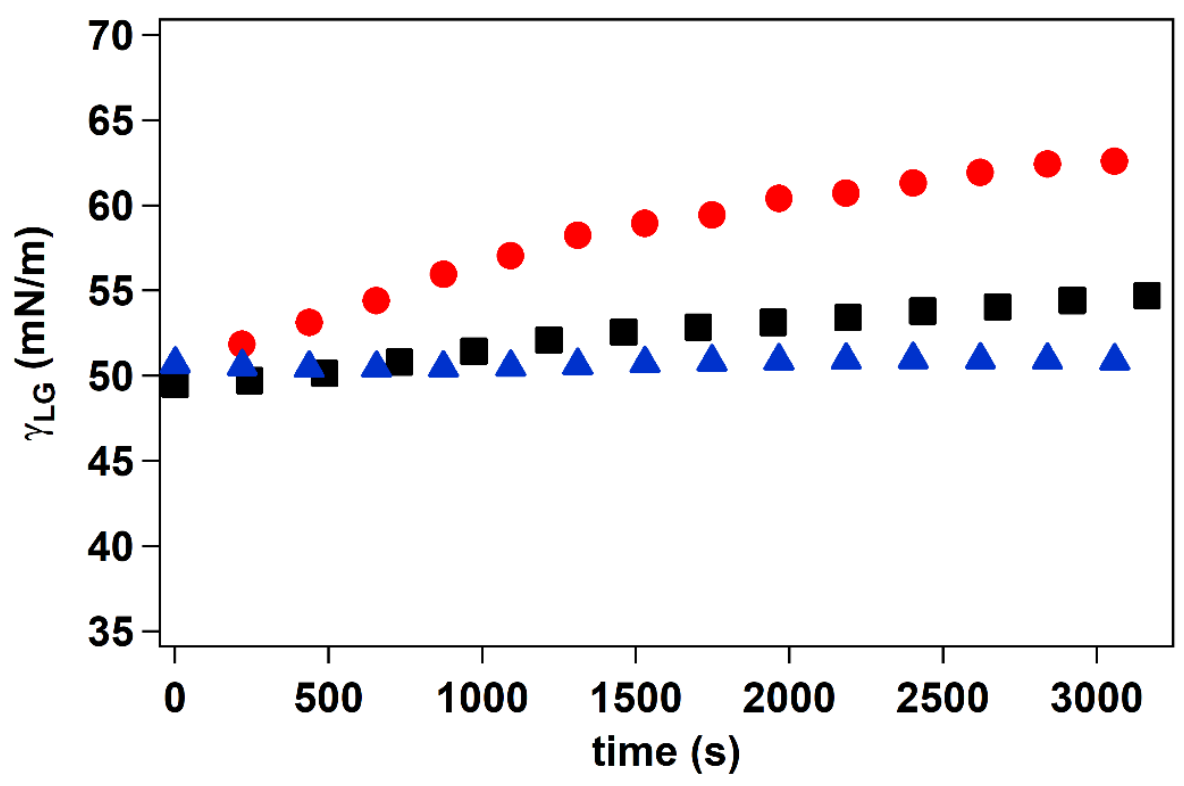

Figure 5. Liquid-gas interfacial tension as a function of time for $\mathrm{CTA}^{+} \mathrm{OH}^{-}$at $C=0.5 \mathrm{mM}$ in the presence of $d=7$ $\mathrm{nm}(),, d=4 \mathrm{~nm}(!)$ and $d=2 \mathrm{~nm}(7)$ porous silica particles (1.2 $\mathrm{g}$ of particles in $35 \mathrm{~mL})$.

Knowing the initial $\mathrm{CTA}^{+} \mathrm{OH}^{-}$surfactant concentration $C$ and the interfacial tension $\gamma_{\mathrm{LG}}$ after adsorption (at time $t=3000 \mathrm{~s}$ in Figure 4 and 5), we can extract the final surfactant concentration $C_{\mathrm{f}}$ in the solution using the $\gamma_{\mathrm{LG}}$ vs $C$ data (eventually interpolated) shown in Figure 1A. Hence, we can calculate the total mass of surfactant removed in the $V=35 \mathrm{~mL}$ solution as $\left(C-C_{\mathrm{f}}\right) V$. In Figure 6A, the adsorption amount (which is the mass of surfactants divided by the mass of porous particles) is plotted as a function of the initial surfactant concentration. For $d=7 \mathrm{~nm}$ porous silica particles, the adsorption amount increases up to $2 \mathrm{mg} / \mathrm{g}$ at intermediate concentrations. For $d=4 \mathrm{~nm}$ porous silica particles instead a maximum in the adsorption amount is clearly observed at $C=0.25 \mathrm{mM}$, above which the adsorption amount decreases. Knowing the mass $m(=1.2 \mathrm{mg})$ of the porous particles and their specific areas $S_{\mathrm{A}}$ (see Materials and Methods), we can also calculate the surfactant surface concentration $\Gamma_{\mathrm{S}}$ on the total silica area $\left(=m S_{\mathrm{A}}\right)$ :

$\Gamma_{S}=\frac{\left(c-C_{f}\right) V}{m S_{A}}$

Figure $6 \mathrm{~B}$ shows $\Gamma_{\mathrm{S}}$ as a function of $\mathrm{CTA}^{+} \mathrm{OH}^{-}$concentration for $d=4$ and $7 \mathrm{~nm}$ porous silica particles. For $C=0.1 \mathrm{mM}$, we measured a weak adsorption of surfactants on porous silica particles $\Gamma_{\mathrm{S}}=1-3 \mathrm{mg} / \mathrm{m}^{2}$, which is equivalent to the surface excess of $\mathrm{CTA}^{+}$surfactant forming dense monolayers at the interface. For non-spherical silica particles with $d=7 \mathrm{~nm}, \Gamma_{\mathrm{S}}$ increases up to $10 \mathrm{mg} / \mathrm{m}^{2}$ at intermediate concentrations and slightly decreases if $C$ approaches the CMC $(\approx 0.9 \mathrm{mM})$. For spherical silica particles with $d=4 \mathrm{~nm}$, the surface concentration increases up to $\Gamma_{\mathrm{S}} \approx 4 \mathrm{mg} / \mathrm{m}^{2}$ and significantly decreases if $C$ approaches the CMC. It is interesting to note that at low concentrations, $\Gamma_{\mathrm{S}}$ is proportional to the pore size, meaning that pores are filled with surfactants. In this pore size range and for surfactant concentrations far from the $\mathrm{CMC}$, the larger the pore diameter the larger the surfactant adsorption. Close to the CMC however surfactants start to self-assemble in the form of micelles in the volume. As a consequence, a competition between the self-assembly of surfactants in the volume and the adsorption inside the pores of the silica particles is expected. This competition may also depend on the confinement 
292 dictated by the pore size. If the pore confinement effect is very strong, micelles in the volume could 293 hinder surfactant adsorption inside the particles' pores. For $d=4 \mathrm{~nm}$ porous particles, the decrease of $\Gamma_{\mathrm{S}}$ 294 as a function of concentration seems in agreement with this scenario. For pore size $d=7 \mathrm{~nm}$, the pore 295 confinement effect is weaker than for $d=4 \mathrm{~nm}$ given that the micellar dimensions are about $3.5 \mathrm{~nm}$, i.e. 296 the half of the pore size, which explains the weak decrease of $\Gamma_{\mathrm{S}}$ as a function of concentration close to 297 the CMC, see Figure 6B.

298

A

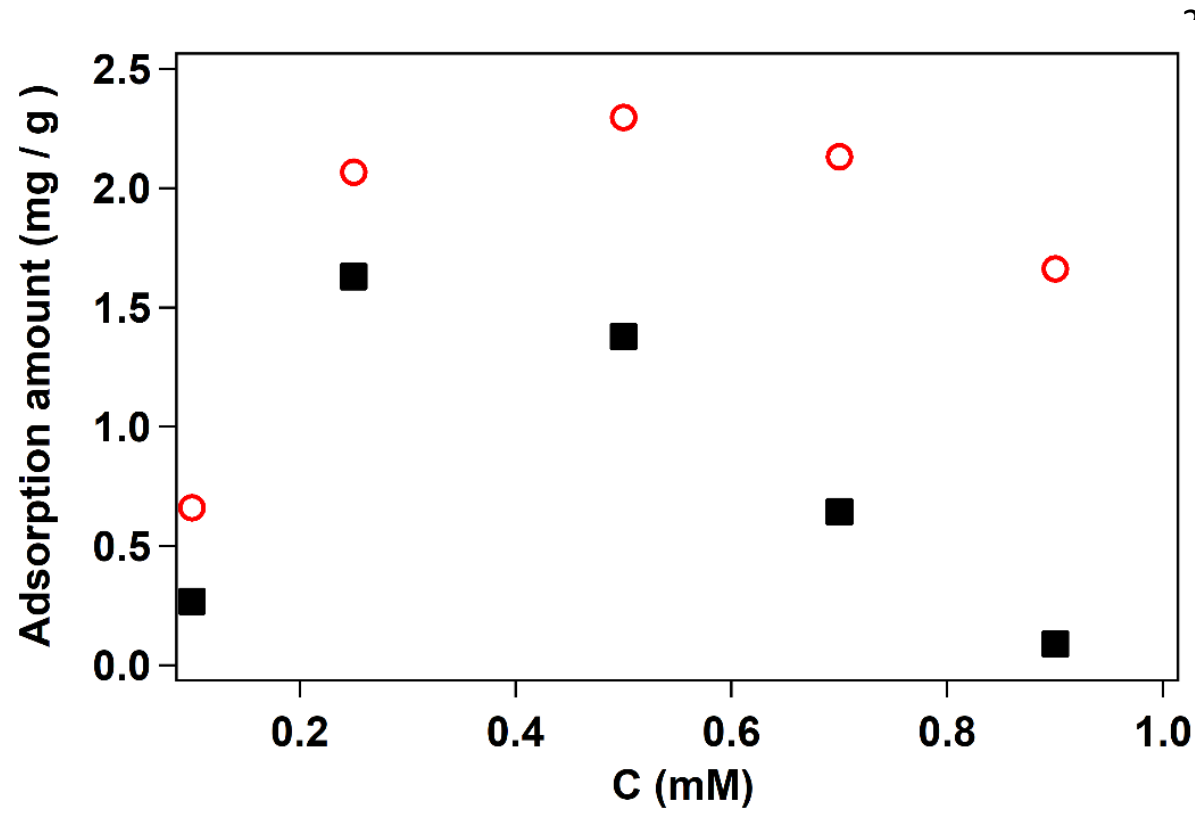

A

310

B

311

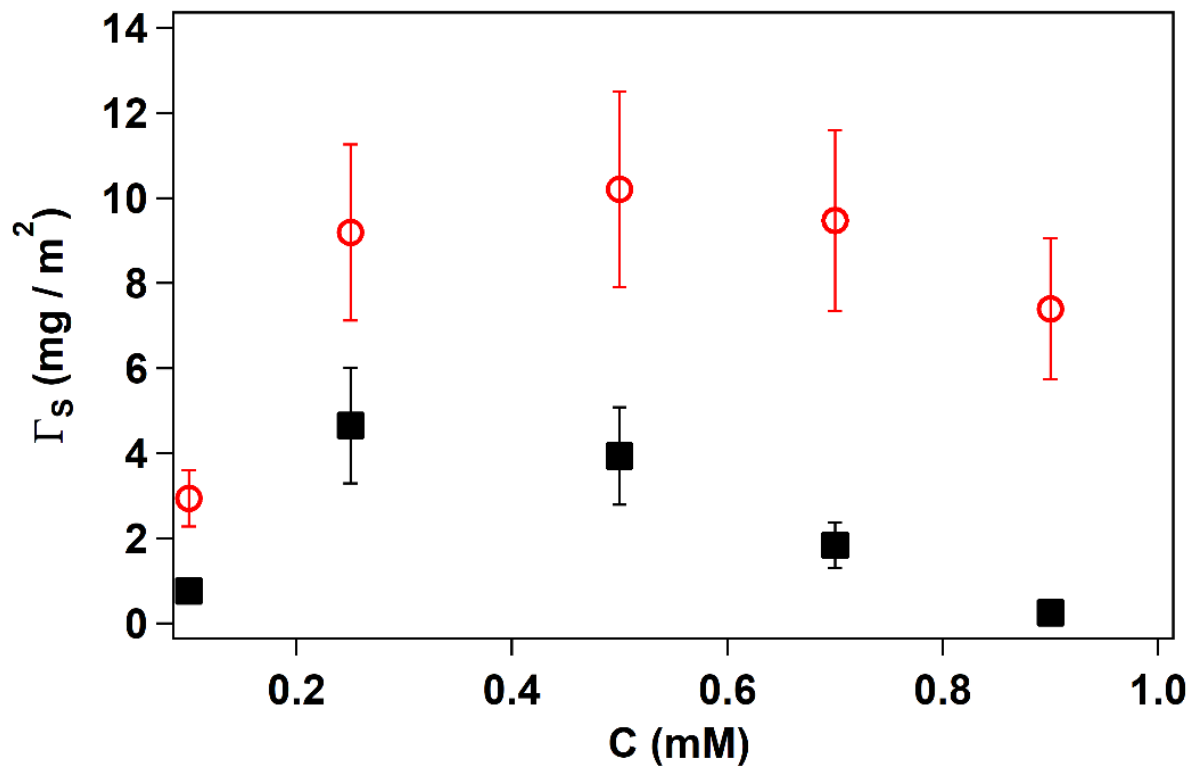

B 
Figure 6. Adsorption amount (A) and surfactant excess concentration on the total silica Area (B) for $d=7 \mathrm{~nm}(-)$, and $d=4 \mathrm{~nm}$ (!) solid particles as a function of $\mathrm{CTA}^{+} \mathrm{OH}^{-}$initial concentration.

\section{Porous particle diffusion at the gas-liquid interface}

At the single colloidal particle level, we have also noticed striking differences in the translational diffusion of spherical $d=4 \mathrm{~nm}$ porous particle at the gas-liquid interface in the absence and the presence of $\mathrm{CTA}^{+}$surfactants. Tracking the particle center of mass at the air-water interface, we observed Brownian trajectories (see inset Figure 7A) and measured the mean squared displacement $(M S D)$, which is plotted as a function of the lag time $\Delta t$ in Figure 7A. Translational diffusion coefficients at the surface, $D_{\mathrm{s}}$ : can be calculated by $M S D=4 D_{\mathrm{s}} \Delta t$.

In absence of surfactants, $D_{\mathrm{s}}$ for $d=2$ and $4 \mathrm{~nm}$ pore particles agrees with the hydrodynamic prediction for partially immersed particles at clean and flat fluid interface, see Figure $7 \mathrm{~B}:{ }^{40}$

$D_{S}=\frac{k_{B} T}{k_{t} \eta R}$

where $k_{\mathrm{B}} T$ is the thermal agitation energy, $\eta$ is the liquid viscosity and $k_{t}$ is the drag factor accounting for the particle immersion or contact angle at the interface: ${ }^{40}$

$k_{t}=3 \pi\left[1+\frac{9}{16} \cos \alpha+\mathcal{O}\left(\cos ^{2} \alpha\right)\right]\left(\right.$ for $\left.0<\alpha<90^{\circ}\right)$.

For the particle diffusing in the bulk our experimental results agree with the Stokes-Brownian diffusion $D_{0}=\frac{k_{B} T}{6 \pi \eta R}=0.174 \mu \mathrm{m}^{2} / \mathrm{s}$. In absence of surfactants, the good agreement between the $1.4<D_{\mathrm{S}} / D_{0}<1.5$ experiments and the prediction shows that no additional dissipation due to contact line fluctuations (as observed for bare silica colloids with $\left.1.2<D_{\mathrm{S}} / D_{0}<1.3\right)^{41}$ occur on partially wetted porous particles. As pointed out before the external porous particle surface can be regarded as a composite surface made of hydrophilic silica and fluids. Hence, this surface presents less defects than the surface of a bare particle, which may explain the negligible line friction due to surface defects. ${ }^{41}$ As a perspective, one may wonder if these porous particles could be good probes for passive surface microrheology since the only sources of dissipations seem to be the viscosity.

Surface diffusion coefficients of porous particles change significantly in the presence of $\mathrm{CTA}^{+} \mathrm{OH}^{-}(C=$ $0.5 \mathrm{mM}): 1.1<D_{\mathrm{S}} / D_{0}<1.2$, and in $\mathrm{CTA}^{+} \mathrm{Br}^{-}(C=0.5 \mathrm{mM})$ aqueous solutions: $D_{\mathrm{S}} / D_{0} \approx 0.3$, see Figure 7 . The experiments are performed at times $\approx 3000 \mathrm{~s}$, where an increase of the gas-liquid interfacial tension of $5 \mathrm{mN} / \mathrm{m}$ for $\mathrm{CTA}^{+} \mathrm{OH}^{-}$; and no change for $\mathrm{CTA}^{+} \mathrm{Br}^{-}$were measured, see Figure 4 . Hence the presence of surfactants affect strongly the porous particle translational diffusion at the surface. For porous particles in the presence of $\mathrm{CTA}^{+} \mathrm{OH}^{-}$, adsorption of surfactants inside the pores occurs during the porous particle Brownian motion, whilst in the presence of $\mathrm{CTA}^{+} \mathrm{Br}^{-}$no adsorption dynamics occurs. In order to quantify the decrease of the surface translational diffusion $D_{\mathrm{S}}$, we use a model describing the drag felt by a spherical particle straddling a viscous and incompressible interface possessing a surface viscosity $\eta_{\mathrm{s}}$ at low Boussinesq numbers $B_{0}=\frac{\eta_{s}}{\eta R}<1$. The drag factor in equation 5 in this case reads: ${ }^{42}$

$k_{t}=k_{t}^{(0)}+B_{0} k_{t}^{(1)}+\mathcal{O}\left(B_{0}^{2}\right)$,

$k_{t}^{(0)} \approx 6 \pi \sqrt{\tanh \left[32(1+\cos \alpha) /\left(9 \pi^{2}\right)\right]}$

$k_{t}^{(1)} \approx-4 \ln \left[\frac{2}{\pi} \arctan \left(\frac{(1+\cos \alpha)}{3}\right)\right]$ 
For $\mathrm{CTA}^{+} \mathrm{Br}^{-}(C=0.5 \mathrm{mM})$ aqueous solutions, a surface viscosity $\eta_{\mathrm{s}} \approx 10^{-8}$ Pa.s.m fits well the experimental result. In the literature, a large range of values of $\eta_{\mathrm{S}}$, from $10^{-8}$ to $10^{-6} \mathrm{~Pa} . \mathrm{s} . \mathrm{m}$, are reported for soluble monolayers by surface macrorheology. ${ }^{43}$ Usually a large difference is also measured between surface macro- and micro-rheology $\left(\eta_{\mathrm{S}}=10^{-10} \ldots 10^{-9}\right.$ Pa.s.m $),{ }^{44}$ which could be due to additional dissipations or some boundary conditions not included in the analysis of the results. ${ }^{45,46}$ Recent experiments using noncontact microrheology, with completely wetted particles as probes, report $\eta_{\mathrm{S}}$ $\approx 10^{-8} \ldots 10^{-7}$ Pa.s.m, ${ }^{45}$ which agree with our results for $\mathrm{CTA}^{+} \mathrm{Br}^{-}$. For $\mathrm{CTA}^{+} \mathrm{OH}^{-}$instead our results $\eta_{\mathrm{S}} \approx$ $5.10^{-10}$ Pa.s.m are comparable to passive surface microrheology using partially wetted particles as probe particles. ${ }^{44}$ Given that the liquid-gas interfacial tensions are similar for $\mathrm{CTA}^{+} \mathrm{Br}^{-}$and $\mathrm{CTA}^{+} \mathrm{OH}^{-}$, one possible explanation of the difference in $D_{\mathrm{S}}$ between the two surfactant solutions is related to the surfactant dynamics occurring at the porous particle surface. As already pointed out before, the adsorption of $\mathrm{CTA}^{+} \mathrm{OH}^{-}$surfactants inside the pores could lead to a local depletion of the surfactant concentration close to the external surface of the porous particle and therefore in a smaller surface viscosity felt by the
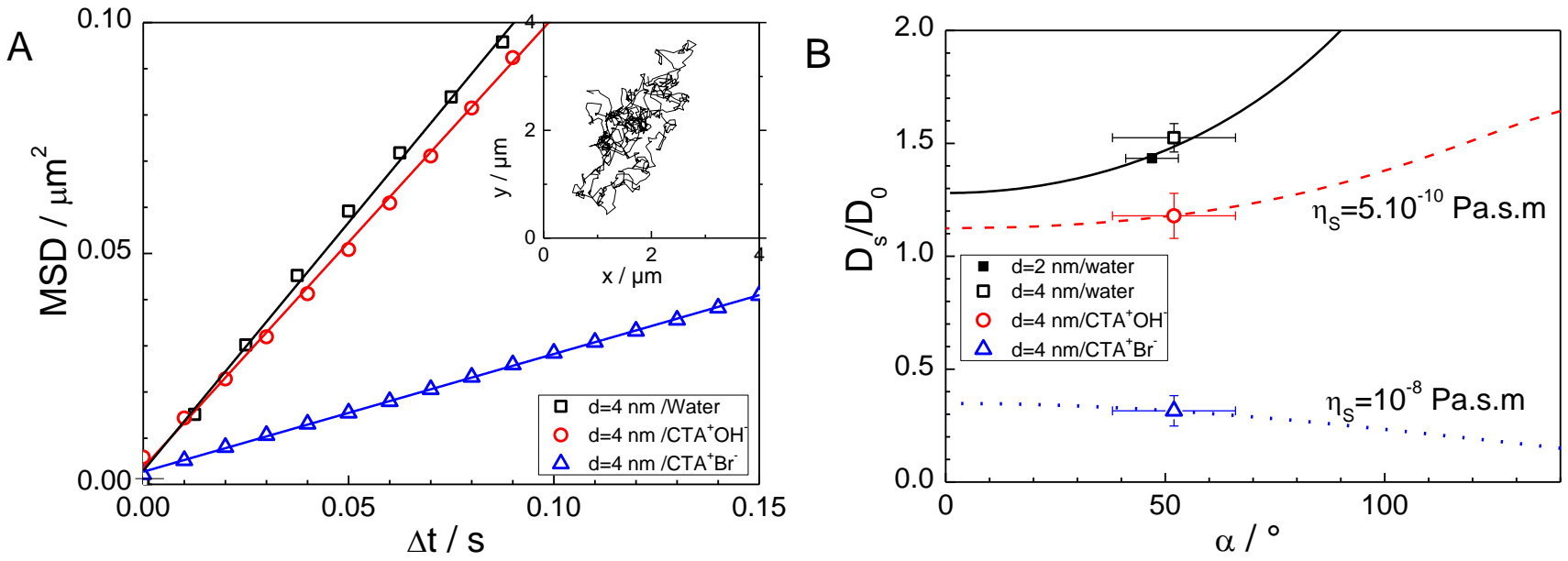

373 particle.

Figure 7. (A) Mean squared displacement as a function of the lag time for $d=4 \mathrm{~nm}$ porous particles at the gas-liquid interface in pure water $(\forall)$, in $C=0.5 \mathrm{mM} \mathrm{CTA}^{+} \mathrm{OH}^{-}$aqueous solution $(-)$and in $C=0.5 \mathrm{mM} \mathrm{CTA}^{+} \mathrm{Br}^{-}$aqueous solution (8). The inset shows a typical particle Brownian trajectory at the surface. (B) Ratio between the surface and the bulk diffusion coefficients as a function of the particle contact angle for the same systems shown in (A) and for $d$ $=2 \mathrm{~nm}$ porous particles at the gas-liquid interface in pure water (!). Solid line is the hydrodynamic prediction for a bare and clean interface. Dashed and pointed lines are drawn from a model valid for viscous and incompressible interfacial layers with a given surface viscosity $\eta_{\mathrm{s}}$.

\section{Influence of the counterion on surfactant adsorption}

We start this section by analysing the remarkable difference in surfactant adsorption on porous particles observed between $\mathrm{CTA}^{+} \mathrm{OH}^{-}$and $\mathrm{CTA}^{+} \mathrm{Br}^{-}$. For planar non-porous interfaces, both interfacial tensions at the liquid-solid and liquid-gas point to a very similar behaviour for $\mathrm{CTA}^{+}$surfactants, independently from the counterions. However, $\mathrm{CTA}^{+} \mathrm{Br}^{-}$surfactants do not adsorb on $d=4$ and $7 \mathrm{~nm}$ porous particles, while 
$388 \mathrm{CTA}^{+} \mathrm{OH}^{-}$surfactants adsorb with very high surface excess concentrations $\approx 4-10 \mathrm{mg} / \mathrm{m}^{2}$ for $C$ around 0.5 $389 \mathrm{mM}$.

390 To explain this striking different behavior we started to look at the $\mathrm{pH}$ of the solution. Adding $391 \mathrm{CTA}^{+} \mathrm{OH}^{-}$surfactants in the solution in fact alters the $\mathrm{pH}$ of water, which changes from 6.4 to 10.5 for $C$ $392=0.5 \mathrm{mM}$. It is also well known that for planar silica surfaces, cationic surfactant adsorption usually 393 increases if the $\mathrm{pH}$ increases because of the increase negative charge of the silica surface. ${ }^{35}$ In order to test 394 this hypothesis, we have added $\mathrm{Na}^{+} \mathrm{OH}^{-}$to a $\mathrm{CTA}^{+} \mathrm{Br}^{-}$solution $(C=0.5 \mathrm{mM})$ in the presence of porous 395 particles. The final $\mathrm{pH}$ measured is very similar $(\mathrm{pH}=10.7)$ to the $\mathrm{pH}$ of $\mathrm{CTA}^{+} \mathrm{OH}^{-}$surfactants where a 396 strong adsorption was observed. However also in this case, $\mathrm{CTA}^{+} \mathrm{Br}^{-}$surfactants do not significantly 397 adsorb on porous silica particles, see Figure 8. It is also important to notice that for planar interfaces, $398 \mathrm{CTA}^{+} \mathrm{Br}^{-}$adsorb on silica even if the $\mathrm{pH}$ remains around $6 .{ }^{35}$

399 If $\mathrm{OH}^{-}$ions are not sufficient to trigger surfactant adsorption on porous particles, we consider the opposite 400 scenario for which the ion $\mathrm{Br}^{-}$is able to hinder $\mathrm{CTA}^{+}$adsorption on silica. Therefore, in the presence of 401 porous particles, we measure the surface tension of $\mathrm{CTA}^{+} \mathrm{OH}^{-}$solution adding $1 \mathrm{mM}$ of $\mathrm{Na}^{+} \mathrm{Br}^{-}$. In this 402 case, we observe that the surface tension of $\mathrm{CTA}^{+} \mathrm{OH}^{-}$(in the presence of porous particles) remains 403 constant instead of increasing, see Figure 8. Thus, it confirms that $\mathrm{CTA}^{+}$do not adsorb inside the pores of $404 d=4$ and $7 \mathrm{~nm}$ silica particles if $\mathrm{Na}^{+} \mathrm{Br}^{-}$is present in the aqueous solution. 


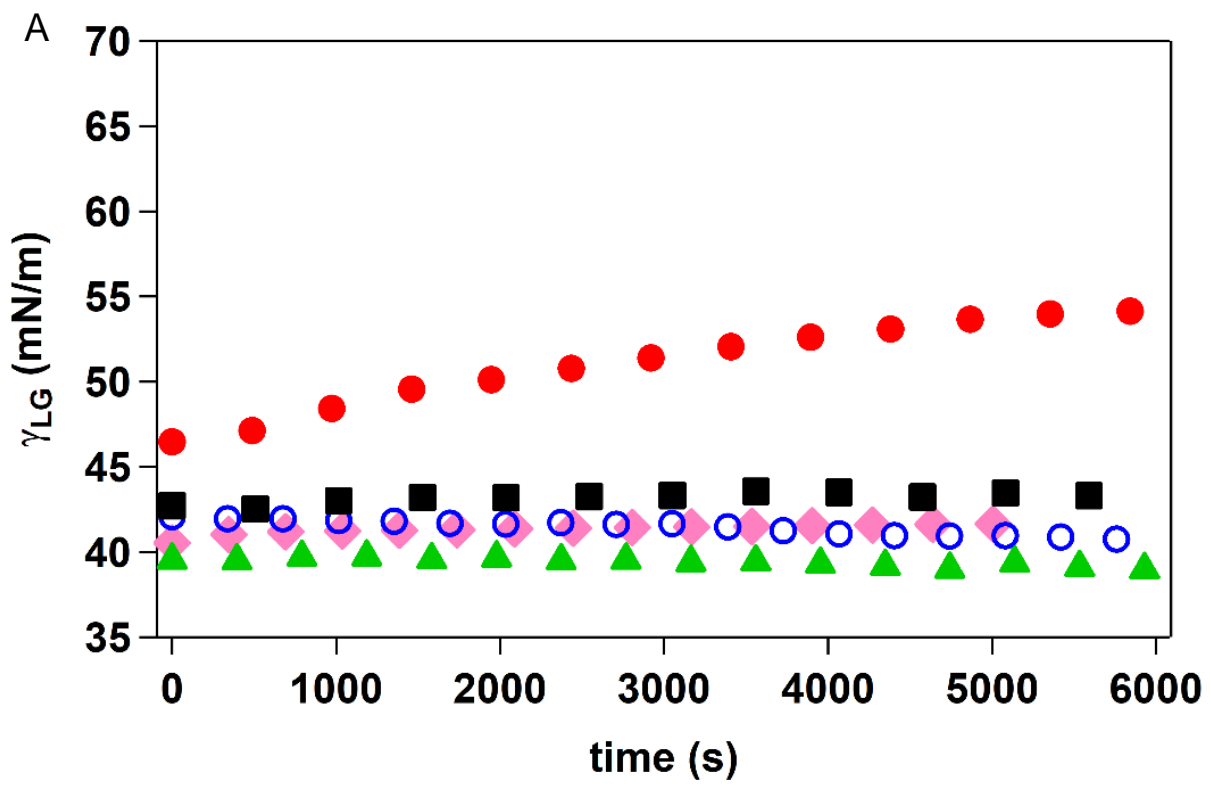

405

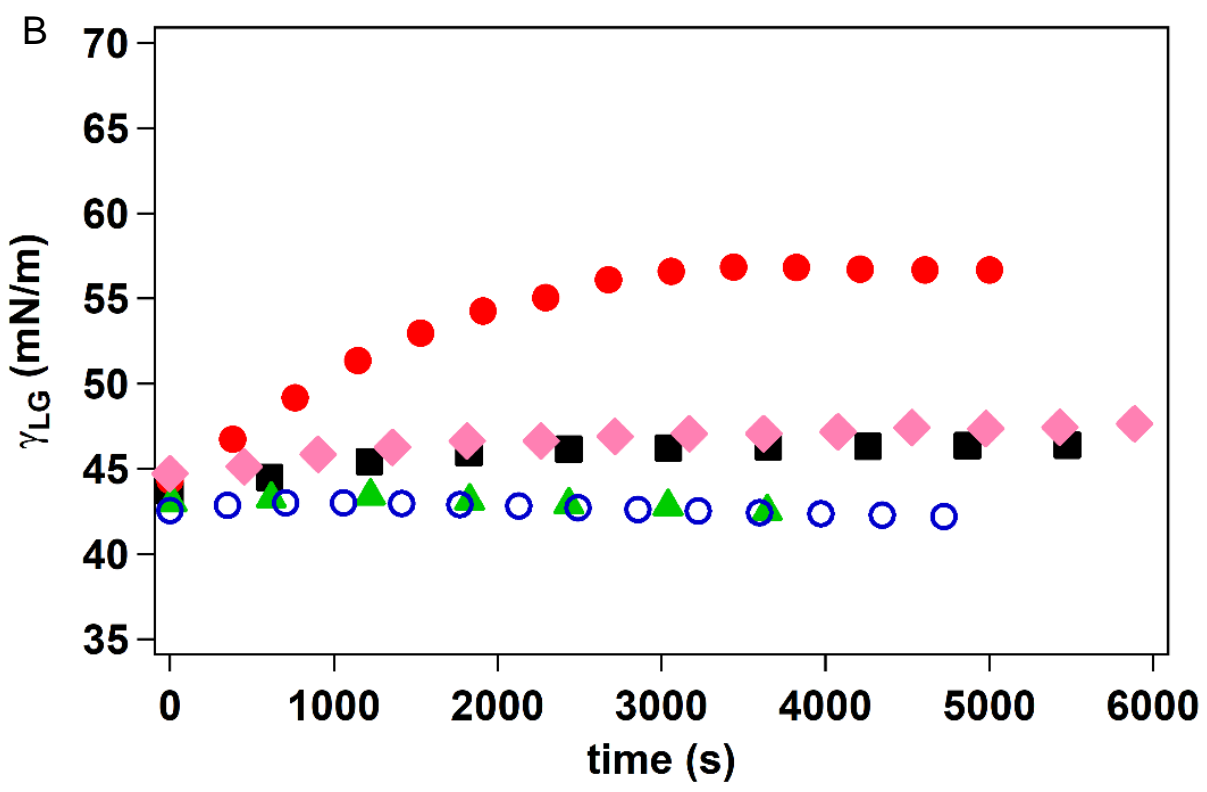

407

Figure 8. Salt effect on the liquid-gas interfacial tension as a function of time after porous particle deposition for $d=$ $4 \mathrm{~nm}$ particles (A) and $d=7 \mathrm{~nm}$ particles (B). The surfactant concentration is fixed, $C=0.5 \mathrm{mM}, \mathrm{CTA}^{+} \mathrm{OH}^{-}$data (,) are the same as in Figure 2. Data for $\mathrm{CTA}^{+} \mathrm{Br}^{--}+\mathrm{NaOH}(!), \mathrm{CTA}^{+} \mathrm{OH}^{-}+[\mathrm{NaBr}]=1 \mathrm{mM}(7), \mathrm{CTA}^{+} \mathrm{OH}^{-}+[\mathrm{NaCl}]$ $=1 \mathrm{mM}(\Lambda)$ and $\mathrm{CTA}^{+} \mathrm{Br}^{-}+[\mathrm{NaCl}]=1 \mathrm{mM}(-)$ as a function of time are also shown.

In order to verify if this effect is specific to $\mathrm{Na}^{+} \mathrm{Br}^{-}$, we have also tested another salt: $\mathrm{Na}^{+} \mathrm{Cl}^{-}$. The surface tension of $\mathrm{CTA}^{+} \mathrm{OH}^{-}$(in the presence of porous particles) in this case increases only by 1 to $3 \mathrm{mN} / \mathrm{m}$, which confirms a salt hindrance effect on adsorption (see Figure 8).

415 Attempting to rationalize these finding, we consider some specific ionic phenomena related to adsorption phenomena. Some properties of $\mathrm{OH}^{-}, \mathrm{Br}^{-}, \mathrm{Cl}^{-}$and $\mathrm{Na}^{+}$are listed in table 1.The main differences between the three negative ions are their hydration numbers $\left(3\right.$ for $\mathrm{OH}^{-}, 2$ for $\mathrm{Cl}^{-}$and just 1 for $\left.\mathrm{Br}^{-}\right)$and their 
Jones-Dole viscosity $B$ coefficients connected to their ability to weaken or strengthen the interfacial water structure close to hydrophobic molecules such as the surfactant tails. $\mathrm{Cl}^{-}$is at the border $\left(B \approx 0 \mathrm{M}^{-1}\right)$ between chaotropic $\mathrm{Br}^{-}\left(B=-0.04 \mathrm{M}^{-1}\right)$ and kosmotropic $\mathrm{OH}^{-}\left(B=+0.18 \mathrm{M}^{-1}\right)$ behaviors. ${ }^{47}{\mathrm{Hence} \mathrm{OH}^{-}}^{-}$ may favor hydrophobic interactions between $\mathrm{CTA}^{+}$hydrophobic groups, which supports the adsorption of surface micelles; whereas $\mathrm{Br}^{-}$leads to a weakening of these hydrophobic interactions. We have also measured the zeta potential $\zeta$ on bare porous particles, ${ }^{48,49}$ which shows always negative values: $\zeta=-28.5$ $\mathrm{mV}$ for $d=4 \mathrm{~nm}$ and $\zeta=-7.8 \mathrm{mV}$ for $d=7 \mathrm{~nm}$; as expected for hydrophilic silica. ${ }^{50}$ For $\mathrm{CTA}^{+} \mathrm{OH}^{-}$ surfactants, $\zeta$ remains negative for $C=0.25 \mathrm{mM}$ : $\zeta=-19.5 \mathrm{mV}$ for $d=4 \mathrm{~nm}$ and $\zeta=-7.8 \mathrm{mV}$ for $d=7$ $\mathrm{nm}$ particles. On the contrary, in the presence of $\mathrm{CTA}^{+} \mathrm{Br}^{-}$, positive zeta potentials were measured at the same concentration $(C=0.25 \mathrm{mM}): \zeta=+5.3 \mathrm{mV}$ for $d=4 \mathrm{~nm}$ and $\zeta=+5.9 \mathrm{mV}$ for $d=7 \mathrm{~nm}$ particles, which points to the accumulation of positive charges on the external surface of the porous silica colloids. Hence, $\mathrm{CTA}^{+}$from $\mathrm{CTA}^{+} \mathrm{Br}^{-}$(or $\mathrm{H}_{3} \mathrm{O}^{+}$) may accumulate on the silica portion of the porous particle outer surface. This outer silica surface is very small with respect to the total porous particle surface, which may explain the negligible change of the interfacial tension (or $\mathrm{pH}$ ) observed in the experiments. Both the chaotropic effect of $\mathrm{Br}^{-}$and the repulsion due to the positive $\zeta$ lead to a hindrance of $\mathrm{CTA}^{+}$adsorption inside the pores, which could explain the weak adsorption of $\mathrm{CTA}^{+} \mathrm{Br}^{-}$surfactants on porous silica colloids.

Some additional specific ion effects occur on the surface of silica, where silanol groups are known to undergo ion exchange reaction: ${ }^{50,51} \mathrm{X}^{+}+\mathrm{SiOH}=\mathrm{X}(\mathrm{SiO})+\mathrm{H}^{+}$for $\mathrm{pH}<8$, where $\mathrm{X}^{+}$is a cation $\left(\mathrm{H}_{3} \mathrm{O}^{+}\right.$, $\mathrm{Na}^{+}$or $\mathrm{CTA}^{+}$), and for $\mathrm{pH}>8, \mathrm{SiOH}+\mathrm{OH}^{-}=\mathrm{SiO}^{-}$. Hence a competition between $\mathrm{H}_{3} \mathrm{O}^{+}, \mathrm{Na}^{+}$or $\mathrm{CTA}^{+}$ cations is also expected. $\mathrm{Na}^{+}$from $\mathrm{Na}^{+} \mathrm{Br}^{-}$and $\mathrm{Na}^{+} \mathrm{Cl}^{-}$in fact competes with $\mathrm{CTA}^{+}$in the adsorption on silica, ${ }^{52}$ which can explain the weakening of $\mathrm{CTA}^{+} \mathrm{OH}^{-}$adsorption in the presence of a sodium salt (see Figure 8). Note that similarly to $\mathrm{OH}^{-}, \mathrm{Na}^{+}$possesses an elevated hydration number and a positive $B$ coefficient corresponding to a kosmotropic behavior, see Table 1.

\begin{tabular}{|l|c|c|c|c|}
\hline & $\mathrm{OH}^{-}$ & $\mathrm{Br}^{-}$ & $\mathrm{Cl}^{-}$ & $\mathrm{Na}^{+}$ \\
\hline Bare ion radius $(\mathrm{nm})^{53}$ & 0.176 & 0.195 & 0.181 & 0.095 \\
\hline Hydrated radius $(\mathrm{nm})^{53}$ & 0.3 & 0.33 & 0.291 & 0.36 \\
\hline Hydration number $(+/-1)^{53}$ & 3 & 1 & 2 & $4-5$ \\
\hline$B\left(\mathrm{M}^{-1}\right)^{47}$ & +0.18 & -0.04 & -0.01 & +0.06 \\
\hline
\end{tabular}

Table 1

\section{CONCLUSIONS}

We have herein reported some fundamental aspects of the wetting and surface diffusion of porous particles at the liquid-gas interface and explored the mechanisms underlying cationic surfactant adsorption inside the particle's pores. Contact angle of porous particles at the gas-liquid interface can be described in the framework of the Cassie model in partial wetting, and it depends strongly on the presence of the liquid inside the pores of the particle. For pores completely filled by the liquid, the particle contact angle is expected to be very low and porous particles may detach from the interface and diffuse in the bulk. Particle translational diffusion at the pure water interface agrees with the hydrodynamics prediction, 
which makes these particles ideal probes for interfacial microrheology. Porous silica colloids are already able to adsorb efficiently $\mathrm{CTA}^{+} \mathrm{OH}^{-}$surfactants without any chemical surface treatments on silica. We determined a significant adsorption of $\mathrm{CTA}^{+} \mathrm{OH}^{-}$surfactant on $d=4$ and $7 \mathrm{~nm}$ pore size colloids. The lack of adsorption for $d=2 \mathrm{~nm}$ porous particles agrees with the presence of surface micelles and not monolayers of surfactants inside the pores of silica. We quantified $\mathrm{CTA}^{+} \mathrm{OH}^{-}$surface concentration and showed that for $C<\mathrm{CMC}$, the adsorption increases with the pore size. Therefore, we investigated the effect of the counterion on surfactant removal in order to understand the opposite adsorption behaviour observed between $\mathrm{CTA}^{+} \mathrm{OH}^{-}$and $\mathrm{CTA}^{+} \mathrm{Br}^{-}$on porous silica colloids. $\mathrm{pH}$ and surface charge effects are not able alone to explain our experimental findings, which points to the importance of kosmotropic/chaotropic counterion character. Surfactant adsorption on the porous particle affects also the particle translational diffusion at the interface, which points to different boundary conditions on the particle external surface.

Finally, these results can be used to implement an environmental friendly strategy to remediate the surface of water from soluble and insoluble pollutants. Yet for future investigations, we plan to functionalize porous silica particles with hydrophobic groups to target contaminants that accumulate preferentially only on the water surface. Moreover, based on our expertise on self-propelled Janus silica particles at the interface, ${ }^{54,55}$ we plan to investigate the role of enhanced active diffusion on the kinetic of surfactant removal. ${ }^{56}$ Attention will be paid to the effect of ionic species present in the aqueous medium on the self-propulsion particle behavior. ${ }^{57,58}$

\section{ASSOCIATED CONTENTS}

Supporting information

Non-spherical mesoporous silica particles pore size distribution, Particle deposition protocols.

\section{ACKNOWLEDGEMENTS}

This article is dedicated to the memory of Giancarlo Stocco (1941-2019). We acknowledge Labex Chemisyst (ANR-10- LABX-05-01) and the University of Montpellier for financial supports. We want also to thank Thomas Zemb, Olivier Diat, Gaelle Gassin, Martin In, Julian Oberdisse and Michael Gradzielski for discussions. We acknowledge Clarence Charnay for zeta potential experiments and Frederic Fernandez "University of Montpellier, Platform MEA" for the SEM microscopy. Finally, financial supports from the ANR SURFANICOL ANR-14-CE07-0039-01 is also acknowledged. 


\section{References}

(1) Heinz, H.; Pramanik, C.; Heinz, O.; Ding, Y.; Mishra, R. K.; Marchon, D.; Flatt, R. J.; Estrelalopis, I.; Llop, J.; Moya, S.; et al. Nanoparticle Decoration with Surfactants : Molecular Interactions, Assembly, and Applications. Surf. Sci. Rep. 2017, 72 (1), 1-58.

(2) Paria, S.; Khilar, K. C. A Review on Experimental Studies of Surfactant Adsorption at the Hydrophilic Solid - Water Interface. Adv. Colloid Interface Sci. 2004, 110, 75-95.

(3) Olkowska, E.; Ruman, M.; Polkowska, Z. Occurrence of Surface Active Agents in the Environment. J. Anal. Methods Chem. 2014, 2014, 769708.

(4) Li, Z.; Bowman, R. S. Counterion Effects on the Sorption of Cationic Surfactant and Chromate on Natural Clinoptilolite. Environ. Sci. Technol. 1997, 31 (8), 2407-2412.

(5) Kotti, M.; Papafilippaki, A.; Prassa, P.; Xirouhaki, A. Removal of Cationic Surfactants from Water by Adsorption on Attapulgite. Comput. Water, Energy, Environ. Eng. 2018, 07 (03), 111118.

(6) Maria-Hormigos, R.; Pacheco, M.; Jurado-Sánchez, B.; Escarpa, A. Carbon Nanotubes-FerriteManganese Dioxide Micromotors for Advanced Oxidation Processes in Water Treatment. Environ. Sci. Nano 2018, 5 (12), 2993-3003.

(7) Das, S.; Chakraborty, J.; Chatterjee, S.; Kumar, H. Prospects of Biosynthesized Nanomaterials for the Remediation of Organic and Inorganic Environmental Contaminants. Environ. Sci. Nano 2018, 5 (12), 2784-2808.

(8) Yang, K.; Wang, J.; Chen, X.; Zhao, Q.; Ghaffar, A.; Chen, B. Application of Graphene-Based Materials in Water Purification: From the Nanoscale to Specific Devices. Environ. Sci. Nano 2018, 5 (6), 1264-1297.

(9) Goloub, T. P.; Koopal, L. K.; Bijsterbosch, B. H.; Sidorova, M. P. Adsorption of Cationic Surfactants on Silica . Surface Charge Effects. Langmuir 1996, 7463 (8), 3188-3194.

(10) Atkin, R.; Craig, V. S. J.; Wanless, E. J.; Biggs, S. Mechanism of Cationic Surfactant Adsorption at the Solid - Aqueous Interface. Adv. Colloid Interface Sci. 2003, 103 (03), 219-304.

(11) Rennie, A.; Lee, E.; Simister, E.; Thomas, R. Structure of Cationic Surfactant Layer at the SilicaWater Interface. Langmuir 1990, 6, 1031-1034.

(12) Tyrode, E.; Rutland, M. W.; Bain, C. D. Adsorption of CTAB on Hydrophilic Silica Studied by Linear and Nonlinear Optical Spectroscopy. J. Am. Chem. Soc. 2008, 130 (51), 17434-17445.

(13) Atkin, R.; Craig, V. S. J.; Biggs, S. Adsorption Kinetics and Structural Arrangements of Cationic Surfactants on Silica Surfaces. Langmuir 2000, 16 (8), 9374-9380.

(14) Biswas, S. C.; Chattoraj, D. K. Kinetics of Adsorption of Cationic Surfactants at Silica-Water Interface. J. Colloid Interface Sci. 1998, 20 (205), 12-20.

(15) Wangchareansak, T.; Keniry, M. A.; Liu, G.; Craig, V. S. J. Coadsorption of Low-Molecular Weight Aromatic and Aliphatic Alcohols and Acids with the Cationic Surfactant, CTAB, on Silica Surfaces. Langmuir 2014, 30, 6704-6712.

(16) Lehman, S. E.; Larsen, S. C. Zeolite and Mesoporous Silica Nanomaterials: Greener Syntheses, Environmental Applications and Biological Toxicity. Environ. Sci. Nano 2014, 1 (3), 200-213. 
(17) Tang, Z.; Wang, J.; Zhao, T.; Shi, J.; Wu, F.; Giesy, J. P.; Zhang, H.; Zhao, X. Efficient Removal of Both Antimonite ( $\mathrm{Sb}(\mathrm{Iii})$ ) and Antimonate ( $\mathrm{Sb}(\mathrm{v})$ ) from Environmental Water Using Titanate Nanotubes and Nanoparticles. Environ. Sci. Nano 2019, 6, 834-850.

(18) Liu, L.; Yang, X.; Xu, Z.; Liu, L.; Yang, X.; Xu, Z. Gibbs Ensemble Monte Carlo Simulation of Adsorption for Model Surfactant Solution in Confined Slit Pores. J. Chem. Phys. 2008, 128, 184712.

(19) Shin, T.; Dem, B.; Fratzl, P.; Paris, O.; Findenegg, G. H. Surfactant Self-Assembly in Cylindrical Silica Nanopores. J. Phys. Chem. Lett. 2010, 1, 1442-1446.

(20) Shin, T. G.; Dirk, M.; Meissner, J.; Paris, O.; Findenegg, G. H. Structural Characterization of Surfactant Aggregates Adsorbed in Cylindrical Silica Nanopores. Langmuir 2011, 27, 5252-5263.

(21) Qiao, Y.; Scho, M.; Findenegg, G. H. 2H NMR Investigation of the Structure and Dynamics of the Nonionic Surfactant C12E5 Confined in Controlled Pore Glass. Langmuir 2003, 19 (3), 61606167.

(22) Müter, D.; Rother, G.; Bock, H.; Schoen, M.; Findenegg, G. H. Adsorption and Depletion Regimes of a Nonionic Surfactant in Hydrophilic Mesopores : An Experimental and Simulation Study. Langmuir 2017, 33, 11406-11416.

(23) Shin, T.; Findenegg, G. H.; Brandt, A. Surfactant Adsorption in Ordered Mesoporous Silica Studied by SANS. Prog. Colloid Polym. Sci. 2006, 133 (May), 116-122.

(24) Kumar, S.; Aswal, V. K.; Kohlbrecher, J. Size-Dependent Interaction of Silica Nanoparticles with Different Surfactants in Aqueous Solution. Langmuir 2012, 28, 9288-9297.

(25) Sharma, K. P.; Aswal, V. K.; Kumaraswamy, G. Adsorption of Nonionic Surfactant on Silica Nanoparticles : Structure and Resultant Interparticle Interactions. J. Phys. Chem. B 2010, 114, 10986-10994.

(26) Ahualli, S.; Iglesias, G. R.; Wachter, W.; Dulle, M.; Minami, D.; Glatter, O. Adsorption of Anionic and Cationic Surfactants on Anionic Colloids : Supercharging and Destabilization. Langmuir 2011, 27, 9182-9192.

(27) Tsubaki, J.; Jimbo, G. A Proposed New Characterization of Particle Shape and Its Application. Powder Technol. 1979, 22 (2), 161-169.

(28) Mouawia, R.; Mehdi, A.; Reyé, C.; Corriu, R. J. P. From Simple Molecules to Highly Functionalised Lamellar Materials. J. Mater. Chem. 2008, 18 (17), 2028-2035. https://doi.org/10.1039/b719162f.

(29) Lotito, V.; Zambelli, T. Self-Assembly of Single-Sized and Binary Colloidal Particles at Air/Water Interface by Surface Confinement and Water Discharge. Langmuir 2016, 32 (37), 9582-9590.

(30) Paunov, V. N. Novel Method for Determining the Three-Phase Contact Angle of Colloid Particles Adsorbed at Air - Water and Oil - Water Interfaces. Langmuir 2003, 19 (13), 7970-7976.

(31) Zorin, Z.; Churaev, N.; Esipova, N.; Sergeeva, I.; Sobolev, V.; Gasanov, E. Influence of Cationic Surfactant on the Surface Charge of Silica and on the Stability of Aqueous Wetting Films. $J$. Colloid Interface Sci. 1992, 152 (1), 170-182.

(32) Binks, B. P. Solid Wettability from Surface Energy Components: Revelance to Pickering Emulsion. Langmuir 2002, 18 (1), 1270-1273. 
(33) Haidara, H.; Owen, M. J. A Direct Method of Studying Adsorption of a Surfactant at Solid-Liquid Interfaces. J. Phys. Chem. 1995, 99, 8681-8683.

(34) Haidara, H.; Vonna, L.; Schultz, J. Kinetics and Thermodynamics of Surfactant Adsorption at Model Interfaces : Evidence of Structural Transitions in the Adsorbed Films. Langmuir 1996, 79 (8), 3351-3355.

(35) Monticone, V.; Treiner, C. Coadsorption of Phenoxyalchohols and Cationic Surfactans with Various Headgroups at the Silica/Water Interface. J. Colloid Interface Sci. 1994, 166, 394-403.

(36) Stocco, A.; Carriere, D.; Cottat, M.; Langevin, D. Interfacial Behavior of Catanionic Surfactants. Langmuir 2010, 26 (13), 10663-10669.

(37) Pyter, R. A. Wetting of Solids by Surface-Active Agents : The Effects of Unequal Adsorption to Vapor-Liquid and Solid-Liquid Interfaces. J. Colloid Interface Sci. 1982, 89 (1), 144.

(38) Rutland, M. W.; Parker, J. L. Surface Forces between Silica Surfaces in Cationic Surfactant Solutions : Adsorption and Bilayer Formation at Normal and High PH. Langmuir 1994, 10 (7), $1110-1121$.

(39) Stocco, A.; Nobili, M. A Comparison between Liquid Drops and Solid Particles in Partial Wetting. Adv. Colloid Interface Sci. 2017, 247, 223-233.

(40) Aaron, D.; Hardt, S. Drag and Diffusion Coefficients of a Spherical Particle Attached to a Fluid Interface. J. Fluid Mech. 2015, 1-11.

(41) Boniello, G.; Blanc, C.; Fedorenko, D.; Medfai, M.; Mbarek, N. Ben; In, M.; Gross, M.; Stocco, A.; Nobili, M. Brownian Diffusion of a Partially Wetted Colloid. Nat. Mater. 2015, 14 (9), 908911.

(42) Fischer, T. M.; Dhar, P.; Heinig, P. The Viscous Drag of Spheres and Filaments Moving in Membranes or Monolayers. J. Fluid Mech. 2006, 558, 451.

(43) Langevin, D. Surface Shear Rheology of Monolayers at the Surface of Water. Adv. Colloid Interface Sci. 2014, 207, 121-130.

(44) Sickert, M.; Rondelez, F.; Stone, H. a. Single-Particle Brownian Dynamics for Characterizing the Rheology of Fluid Langmuir Monolayers. Europhys. Lett. 2007, 79 (6), 66005.

(45) Shlomovitz, R.; Evans, A. A.; Boatwright, T.; Dennin, M.; Levine, A. J. Measurement of Monolayer Viscosity Using Noncontact Microrheology. Phys. Rev. Lett. 2013, 110 (13), 29-33.

(46) Stocco, A.; Chollet, B.; Wang, X.; Blanc, C.; Nobili, M. Rotational Diffusion of Partially Wetted Colloids at Fluid Interfaces. J. Colloid Interface Sci. 2019, 542, 363-369.

(47) Marcus, Y. Effect of Ions on the Structure of Water. Pure Appl. Chem. 2010, 82 (10), 1889-1899.

(48) Kozak, M. W.; Davis, E. J. Electrokinetics of Concentrated Suspensions and Porous Media. 1. Thin Electrical Double Layers. J. Colloid Interface Sci. 1989, 127 (1), 497-510.

(49) Kozak, M. W.; Davis, E. J. Electrokinetics of Concentrated Suspensions and Porous Media. 2 Moderately Thick Electrical Double Layers. J. Colloid Interface Sci. 1989, 129 (1), 166-174.

(50) Allen, L. H.; Matijevic, E. Stability of Colloidal Silica. II Ion Exchange. J. Colloid Interface Sci. 1970, 33, 420-429.

(51) Wängnerud, P.; Olofsson, G. Adsorption Isotherms for Cationic Surfactants on Silica Determined 
by in Situ Ellipsometry. J. Colloid Interface Sci. 1992, 153 (2), 392-398.

607

608

609

610

611

612

613

614

615

616

617

618

619

620

621

622

623

624

625

(52) Dimov, N. K.; Kolev, V. L.; Kralchevsky, P. A.; Lyutov, L. G.; Broze, G.; Mehreteab, A. Adsorption of Ionic Surfactants on Solid Particles Determined by Zeta-Potential Measurements : Competitive Binding of Counterions. J. Colloid Interface Sci. 2002, 256, $23-32$.

(53) Israelachvili, J. N. Intermolecular and Surface Forces; Academic Press, 2011.

(54) Wang, X.; In, M.; Blanc, C.; Nobili, M.; Stocco, A. Enhanced Active Motion of Janus Colloids at the Water Surface. Soft Matter 2015, 11, 7376-7384.

(55) Wang, X.; In, M.; Blanc, C.; Würger, A.; Nobili, M.; Stocco, A. Janus Colloids Actively Rotating on the Surface of Water. Langmuir 2017, 33 (48), 13766-13773.

(56) Safdar, M.; Simmchen, J.; Jänis, J. Light-Driven Micro- and Nanomotors for Environmental Remediation. Environ. Sci. Nano 2017, 4 (8), 1602-1616.

(57) Uygun, D. A.; Jurado-Sánchez, B.; Uygun, M.; Wang, J. Self-Propelled Chelation Platforms for Efficient Removal of Toxic Metals. Environ. Sci. Nano 2016, 3 (3), 559-566.

(58) Eskandarloo, H.; Kierulf, A.; Abbaspourrad, A. Nano- and Micromotors for Cleaning Polluted Waters: Focused Review on Pollutant Removal Mechanisms. Nanoscale 2017, 9 (37), 13850 13863.

\section{TOC graphic}
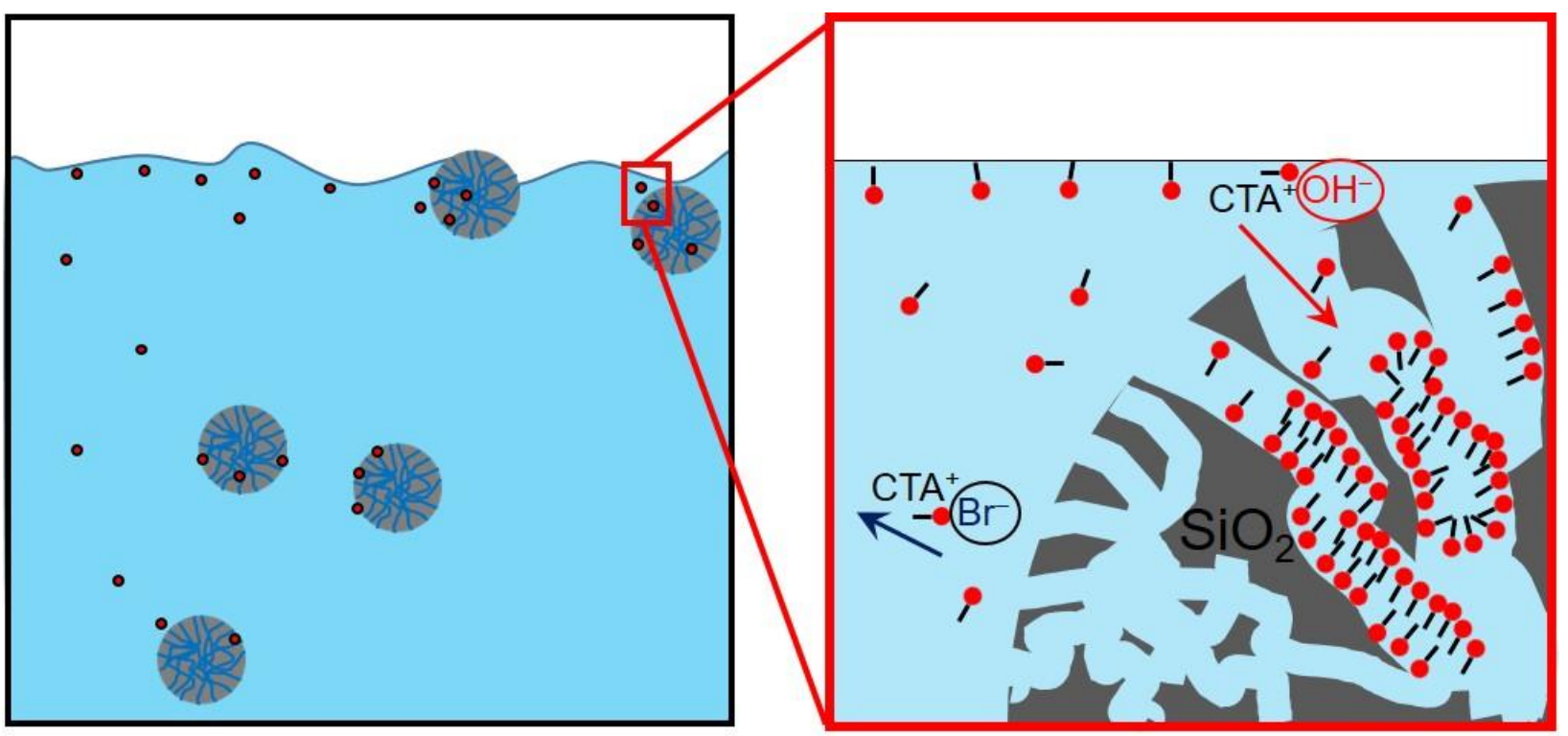